Original Research Article

\title{
WHO core prescribing indicators in patients with allergic contact dermatitis in a coastal town of South India
}

\author{
Divyashanthi C. M. ${ }^{1}$, Bhanu P. Kolasani ${ }^{1}$, Pandiamunian Jayabal ${ }^{1}$, Prasanand Sasidharan ${ }^{2}$, \\ Barathane Datchanamurthy ${ }^{1}$
}

${ }^{1}$ Department of Pharmacology, Vinayaka Missions Medical College, Karaikal, Pondicherry, Tamil Nadu, India

${ }^{2}$ Department of Pharmacology, Dr. SM CSI Medical College,

Karakonam,

Thiruvananthapuram, Kerala, India

Received: 03 December 2016 Accepted: 09 December 2016

*Correspondence to:

Dr. Divyashanthi C. M., Email: dishanthii@gmail.com

Copyright: () the author(s), publisher and licensee Medip Academy. This is an openaccess article distributed under the terms of the Creative Commons Attribution NonCommercial License, which permits unrestricted noncommercial use, distribution, and reproduction in any medium, provided the original work is properly cited.

\begin{abstract}
Background: Prescribing pattern analysis utilizing WHO core drug prescribing indicators can be helpful for the assessing the beneficial and adverse impacts of the prescribed drugs.

Even though many drugs are commonly used in treatment of Allergic contact dermatitis (ACD) they are least studied in terms of prescribing patterns. Hence the present study was planned to analyze the prescribing pattern and study the WHO core prescribing indicators in patients with ACD in our institute.

Methods: A prospective observational study was carried out with prescriptions of 81 outpatients who attended the dermatology OPD with the diagnosis of ACD over a period of six months. Details such as basic demographics, specific drugs prescribed with their dose and dosage forms were recorded and WHO core prescription indicators analysed.

Results: Overall, corticosteroids both topical and systemic were the most commonly prescribed drugs (45.54\%) followed by antihistamines $(30.69 \%)$ and antimicrobials (13.86\%). The most commonly prescribed topical corticosteroid was desonide $(58.82 \%)$, systemic corticosteroid was prednisolone $(47.61 \%)$, antihistamine was cetirizine $(54,83 \%)$ and antimicrobials were cephalosporins (42.86\%). Average drugs per prescription for patients of ACD were 6.8. Percentage of drugs prescribed by generic name was $22.77 \%$. Percentage of encounters with antibiotic prescribed was $13.86 \%$ whereas injection prescribed was $9.90 \%$. Percentage of drugs prescribed from National list of essential medicines (NLEM) was $53.57 \%$.

Conclusions: Corticosteroids remain the mainstay of treatment in ACD. The percentage of encounters with an injection and the use of systemic steroids were low and were according to the guidelines. But drugs prescribed by generic name and those prescribed from NELM were found to be satisfactory but can further be improved.
\end{abstract}

Keywords: Corticosteroids, Generic name, National list of essential medicines, Prescribing pattern, WHO core drug prescribing indicators

\section{INTRODUCTION}

According to World Health Organization (WHO) rational use of drugs is defined as "patients receiving medicines appropriate for their clinical needs, in doses that meet their individual requirements, for an adequate period of time and at the lowest cost to them and their community". ${ }^{1}$ But it is observed that most of the prescribers throughout the world specifically in developing countries like India are not involved in rational use of medicines. Drugs which are ineffective, unnecessary, unrelated to diagnosis, medically inappropriate, expensive and multiple drugs are prescribed. $^{2}$

The ability to choose from various drugs that are available in the market for that particular disease and to determine the ones which will be most suitable for their needs requires a thorough understanding of various aspects of both the disease and the drugs by the treating physician so that the patient has both safe and efficacious drugs in a cost effective manner. Use of irrational drugs has lot of adverse consequences like delay or inability in curing the disease, have more chances of adverse effects, 
loss of man days, increased incidence of morbidity and mortality, emergence of microbial resistance, financial loss to patient and community, loss of patients confidence in the doctor, lowering of health standards of patients and community and perpetuation of public health problem. ${ }^{3}$

Allergic contact dermatitis (ACD) is a common inflammatory skin disorder which involves sensitization of the immune system to a specific allergen with resulting dermatitis. ${ }^{4}$ The prevalence of contact allergy is rising worldwide. ${ }^{5-7}$ Common substances to which ACD can develop include Nickel in various types of jewellery and watches, Rubber products (latex) found in gloves, wrist bands and undergarments, Paraphenylenedeamine (PPDA) found in hair dyes, Chromates found in cement and paints, and finally Poison ivy. Even some drugs such as sulfonamides, neomycin and topical anesthetics like pramoxine can lead to ACD. ${ }^{8}$

Many drugs like topical and systemic corticosteroids, antihistamines, antimicrobials, immunosupressants and emollients are commonly used in treatment of ACD. ${ }^{2}$ However they are the least studied drugs in terms of their prescribing patterns.

Assessment of drug use patterns with the WHO core drug prescribing indicators is becoming increasingly necessary to promote rational drug use in developing countries. ${ }^{9,10}$ Without an accurate understanding of how drugs are being prescribed and used, it is difficult to suggest measures to improve the prescribing habits. ${ }^{11}$ Hence the present study was planned to analyse the prescribing pattern of drugs and WHO core prescribing indicators among patients of ACD in dermatology outpatient department of our institute.

\section{METHODS}

This is a prospective observational study which was carried out in a total of 81 outpatients who attended the dermatology OPD of our institute from February, 2016 to August, 2016 i.e. for a period of six months. Prescriptions of all the patients with age greater than 18 years who were diagnosed to have ACD and those who agreed to participate in the study were included and the prescriptions of patients who were less than 18 years or those with incomplete data and prescriptions of those patients who did not showed interest to participate in the study were excluded from analysis.

A written informed consent to participate in the study was obtained from all the patients who participated in the study. The study protocol confirmed to the ethical guidelines of the 1975 Declaration of Helsinki, and ethical clearance was obtained from Institutional Ethical Committee before commencing the study.

Data were collected regarding the patient's age, sex, total number of drugs prescribed, various classes of drugs prescribed, percentage of individual drugs in each class,
WHO core prescribing indicators, percentage of parentral versus oral drugs and percentage of drugs prescribed by their dosage forms were analyzed. For the purpose of calculation, fixed dose combinations were considered as one single drug.

The WHO core prescribing indicators that were measured include:

1. The average number of drugs prescribed per encounter to measure the degree of polypharmacy was calculated by dividing the total number of different drugs prescribed by the number of prescriptions studied.

2. Percentage of drugs prescribed by generic name to measure the tendency of prescribing by generic name was calculated by dividing the number of drugs prescribed by generic name by total number of drugs prescribed, multiplied by 100 .

3. Percentage of drugs in which an antimicrobial agent was prescribed was calculated to measure the usage of antibiotics. It was calculated by dividing the number antibiotics prescribed by the total number of drugs prescribed, multiplied by 100 .

4. Percentage of injections prescribed was calculated to measure the overall use of commonly overused and costly forms of drug therapy. It was calculated by dividing the total number of injections prescribed by the total number of drugs prescribed, multiplied by 100 .

5. To measure the degree to which the prescribing practices conform to our national drug policy, we have also analyzed the percentage of drugs prescribed from the National List of Essential Medicines (NLEM) of India. Percentage is calculated by dividing number of products prescribed which are in essential drug list of India by the total number of drugs prescribed, multiplied by 100 .

Statistical analysis was primarily descriptive with values mainly expressed as percentages and absolute numbers

\section{RESULTS}

In the present study, 81 patients of ACD received a total of 317 medications during the study period, among which $48(59.26 \%)$ were females and the remaining 33 $(40.74 \%)$ were males. The maximum patients were found to fall in $20-30$ age group $(34.57 \%)$ followed by $30-40$ age group $(27.16 \%)$.

Overall, corticosteroids both topical and systemic were the most commonly prescribed drugs $(45.54 \%)$ followed by antihistamines $(30.69 \%)$ and antimicrobials (13.86\%).

Among the systemic corticosteroids that were prescribed to patients with $\mathrm{ACD}$, prednisolone (47.61\%) was the most commonly prescribed followed by dexamethasone $(28.52 \%)$ and methyl prednisolone (14.28\%) (Figure 1). 


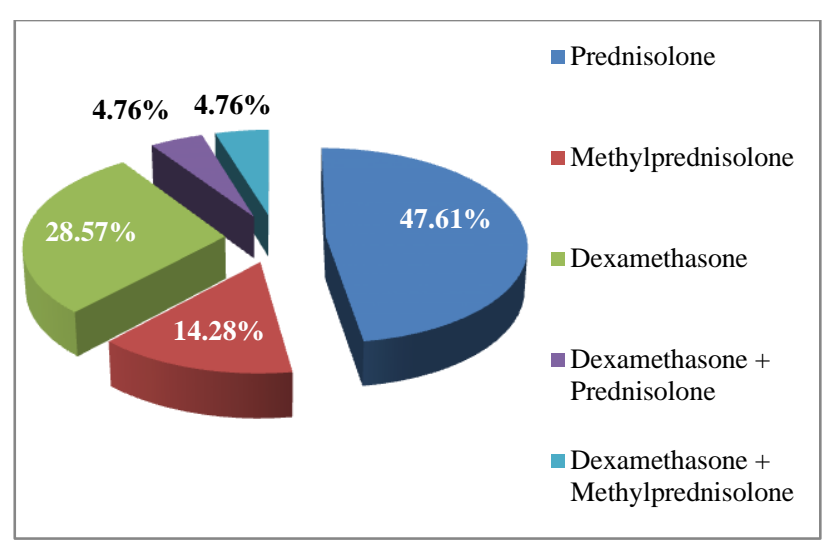

Figure 1: Prescription of systemic corticosteroids among patients of allergic contact dermatitis.

The most commonly prescribed topical corticosteroid among patients with ACD was desonide (55.56\%), followed by mometasone $(33.33 \%)$; clobetasol $(6.17 \%)$ and halobetasol $(3.70 \%)$ were the least prescribed in this category (Figure 2).

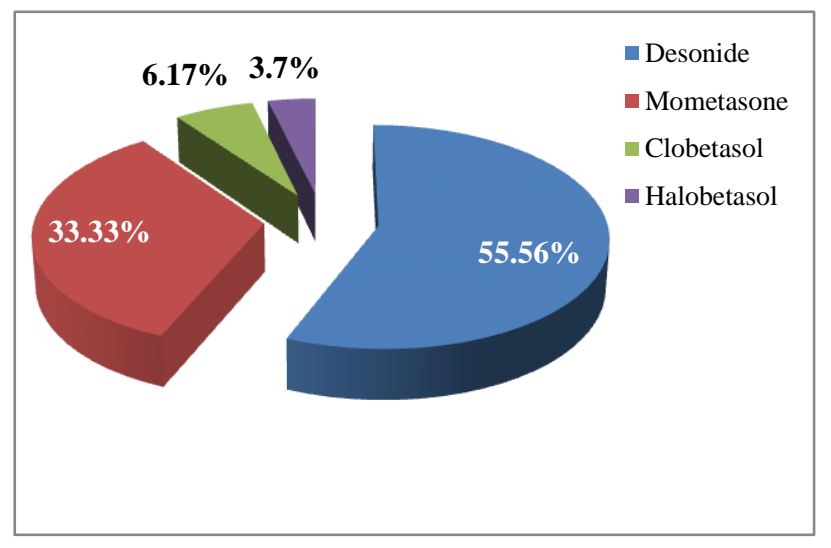

Figure 2: Prescription of topical corticosteroids among patients of allergic contact dermatitis.

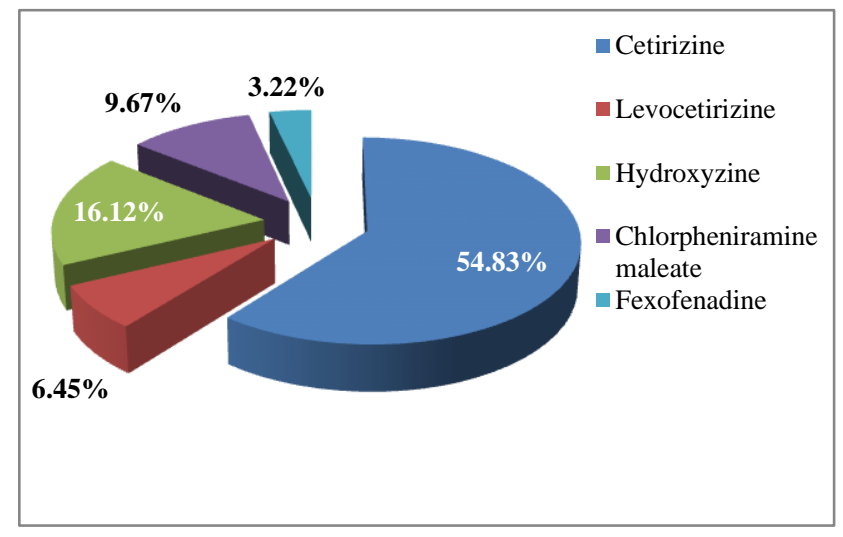

Figure 3: Prescription of antihistamines among patients of allergic contact dermatitis.

With regard to the antihistaminic drugs that were prescribed to patients with ACD cetirizine (54.83\%) was the most commonly prescribed drug followed by Hydroxyzine (16.12\%) and Chlorpheniramine maleate (9.67\%) (Figure 3).

The most commonly prescribed antimicrobial drug among patients with ACD was cefadroxyl (40.30\%) followed by erythromycin $(28.36 \%)$, cefuroxime $(17.91 \%)$, azithromycin $(10.45 \%)$ and amoxicillin + clavulanic acid $(2.99 \%)$ (Figure 4$)$.

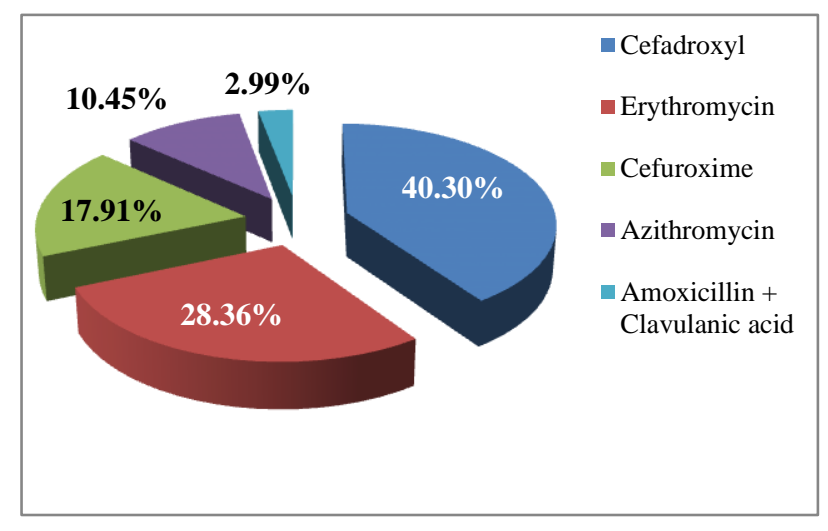

Figure 4: Prescription of antimicrobial drugs among patients of allergic contact dermatitis.

Table 1: WHO core drug prescribing indicators among patients with allergic contact dermatitis.

\begin{tabular}{|lll|}
\hline Sr. No. & Indicator & Value \\
\hline 1 & $\begin{array}{l}\text { Average number of drugs per } \\
\text { prescription }\end{array}$ & 6.8 \\
\hline 2 & $\begin{array}{l}\text { Percentage of drugs prescribed } \\
\text { by generic name }\end{array}$ & $22.77 \%$ \\
\hline 3 & $\begin{array}{l}\text { Percentage of encounters with } \\
\text { antibiotics prescribed }\end{array}$ & $13.86 \%$ \\
\hline 4 & $\begin{array}{l}\text { Percentage of encounters with } \\
\text { an injection prescribed }\end{array}$ & $9.90 \%$ \\
\hline 5 & $\begin{array}{l}\text { Percentage of drugs prescribed } \\
\text { from National essential drug list }\end{array}$ & $53.57 \%$ \\
\hline
\end{tabular}

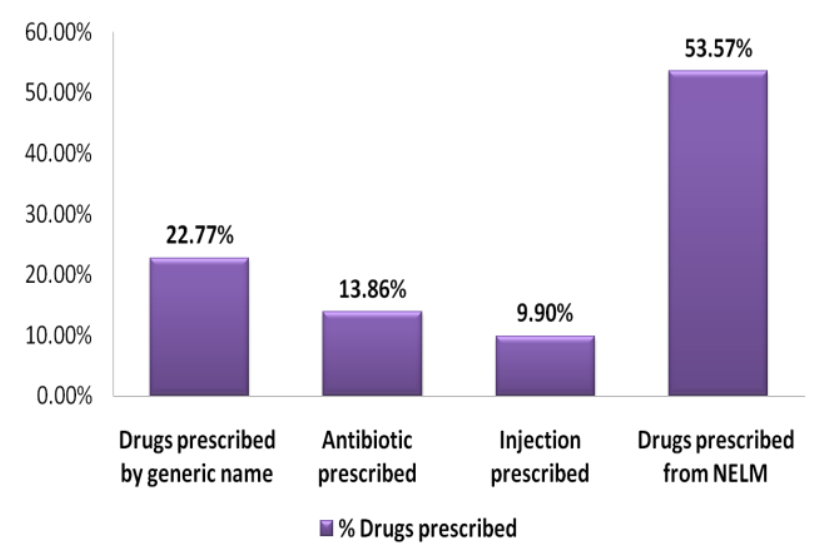

Figure 5: Percentage wise Analysis of WHO core prescribing indicators in patients with allergic contact dermatitis. 
Average drugs per prescription for patients of ACD in our study were found to be 6.8 . Percentage of drugs prescribed by generic name was $22.77 \%$. Percentage of encounters with antibiotic prescribed was $13.86 \%$ whereas the percentage of encounters with an injection was found to be $9.90 \%$. Percentage of drugs prescribed from National list of essential medicines (NLEM) was found to be $53.57 \%$ in our study (Table 1 and Figure 5).

\section{DISCUSSION}

Although, there were few studies done which analyzed the pattern of drug use in patients of ACD, an overwhelming majority of them were carried in other countries. The present study is first of its kind as we have done a comprehensive analysis of all the drugs used in patients of ACD in south India where we have also analyzed the WHO core prescribing indicators as well.

In our study, we found that incidence of ACD was more in females compared to males and majority of cases belonged to 20-30 age group. Contact dermatitis occurs twice as frequently in women as in men and more common in young adults. ${ }^{12,13}$

The best way to prevent recurrence of ACD is avoiding skin contact with substances to which the patient is allergic. ${ }^{14,15}$ Use of antiperspirants and decrease in smoking are other preventive strategies. ${ }^{16}$

In our study, we have found that corticosteroids both topical and systemic were the most commonly prescribed drugs $(45.54 \%)$. Topical steroids are recommended as first-line drugs for management of localized forms of ACD. Selection of a particular steroid must be based on efficacy and potency, by size of lesion, the location of the dermatitis. Localized acute lesions respond better to moderate potency or high potency topical steroids like triamcinolone or clobetasol.

Oral steroids act as immunosuppressive agents and might be indicated for short-term treatment of severe dermatitis. In adults prednisone in a single morning dose of 40 to 60 $\mathrm{mg}$ can be prescribed and tapered over 2 to 3 weeks, as symptoms resolve.

In our study, we have found that antihistamines (30.69\%) were the second most commonly prescribed drugs. Since pruritus is an important complaint of ACD, sedating oral antihistamines might be indicated. Topical antihistamines on the other hand must be discouraged, as they are possible sensitizers. Oral doxepin (10-25 mg at night in adults) can be considered if other oral antihistamines are not helpful. ${ }^{17}$

Acute exudative or bullous lesions can be treated with cool antiseptics compresses, three times a day, and topical steroids. Topical or oral antibiotics must be prescribed in case of secondary bacterial infection. In our study, antimicrobials were found to be the third most common drugs prescribed (13.86\%). In our study, emollients are also prescribed for many patients. Emollients in creams are useful to relief itching and dry skin of ACD.

Various other drugs used in treatment of ACD include Calcineurin inhibitors like Pimecrolimus cream might be used for the face and tacrolimus $0.1 \%$ ointment can be used for ACD of the hands. ${ }^{18,19}$ Some patients with chronic ACD can benefit for PUVA. ${ }^{20}$ Binding agents and barrier creams are substances which promote chelation of substances which provoke ACD, and thus prevent their antigenic properties. They are usually used in combination with others treatments, such as topical steroids. $^{21}$ Barrier creams act as an invisible glove, protecting the skin from environmental allergens. ${ }^{22}$ The most utilized binding agent is ethylene diamine tetraacetic acid (ETDA), which can be included at a $15 \%$ concentration in a cream in association with topical steroids. $^{23}$

In our study, average number of drugs per prescription is 6.8 which was found to be higher compared to a previous study done by Narwane et al, which should be decreased as use of polypharmacy is associated with so many problems like more drug interactions, more adverse effects, decrease in patient compliance, increased incidence of drug resistance and finally increased economic burden on the patients. ${ }^{24}$

In our study, percentage of drugs prescribed by generic names and percentage of drugs from NLEM is much more compared to similar studies done by Anuj et al and Prasad et al which indicates a good trend of prescribing. ${ }^{25,26}$ Even Medical Council of India now mandates all physicians to write the prescriptions in terms of generic names. A higher percentage of drugs from NLEM are more economical so that the drugs become affordable to even the poor patients as essential drugs are cheaper compared to those which are not in the list.

\section{CONCLUSION}

In conclusion, corticosteroids remain the mainstay of treatment in ACD. Average number of drugs per prescription was high which must be decreased as polypharmacy can pose many problems. The percentage of encounters with an injection and the use of systemic steroids were low and were according to the guidelines. Drugs prescribed by generic name and those prescribed from NLEM were found to be satisfactory but can further be improved.

\section{ACKNOWLEDGEMENTS}

Our heartfelt thanks to all the staff of Department of Dermatology for their constant support throughout the study without which this study would not be possible. 
Funding: No funding sources

Conflict of interest: None declared

Ethical approval: The study was approved by the Institutional Ethics Committee

\section{REFERENCES}

1. Tripathi KD. Aspects of pharmacotherapy; clinical pharmacology and drug development. In: Essentials of medical pharmacology. 6thedition. New Delhi: Jaypee Brothers; 2008:68-71.

2. Patel V, Vaidya R, Naik D, Borker P. Irrational drug use in India: A prescription survey from Goa. J Postgrad Med. 2005;51(1):9-12.

3. Mohanty Bk, Aswini M, Hasamnis AA, Patil SS, Murty KSN, Jena SK. Prescription Pattern In Rajahmundry, India. Journal of Clinical and Diagnostic Research. 2010;(4):2047-51.

4. Giri P, Giri OP, Kanodia S. A study on drug prescription pattern in allergic contact dermatitis at tertiary care teaching hospital in south India. $\mathrm{J}$ of Evolution of Med and Dent Sci. 2014;3(43):10683-88.

5. Nguyen SH, Dang TP, MacPherson C, Maibach H, Maibach HI. Prevalence of patch test results from 1970 to 2002 in a multi-centre population in North America (NACDG) Contact Dermat. 2008;58(2):101-6.

6. Kohl L, Blondeel A, Song M. Allergic contact dermatitis from cosmetics. Retrospective analysis of 819 patch-tested patients. Dermatology. 2002;204(4):334-7.

7. Lunder $T$, Kansky A. Increase in contact allergy to fragrances: patch-test results 1989-1998. Contact Dermat. 2000;43(2):107-9.

8. Dutta S, Beg MA, Kumar S. Morbidity profile and drug utilization pattern in allergic diseases in skin outpatients in a tertiary care teaching hospital at Dehradun, Uttarakhanad India. RRJPTS. 2014;2(6):1-6.

9. Hogerzeil HV, Bimo, Ross-Degnan D, Laing RO, OforiAdjei D, Santoso B, et al. Field tests for rational drug use in twelve developing countries. Lancet. 1993;342(8884):1408-10.

10. WHO: How to investigate drug use in health facilities: selected drug use indicators. 1993, Geneva: WHO/DAP/93.1

11. WHO International Working Group for Drug Statistics Methodology, WHO Collaborating Centre for Drug Statistics Methodology, WHO Collaborating Centre for Drug Utilization Research and Clinical Pharmacological Services. Introduction to Drug Utilization Research. Geneva: World Health Organization; 2003:48.

12. Thyssen JP, Linneberg A, Menné T, Johansen JD. The epidemiology of contact allergy in the general population- prevalence and main findings. Contact Dermat. 2007;57(5):287-99.

13. Mortz CG, Lauritsen JM, Bindslev-Jensen C, Andersen KE. Contact allergy and allergic contact dermatitis in adolescents: prevalence measures and associations: the Odense adolescence cohort study on atopic diseases and dermatitis (TOACS) Acta Derm Venereol. 2002;82(5):352-8.
14. Kalimo K, Lammintausta K, Jalava J, Niskanen T. Is it possible to improve the prognosis in nickel contact dermatitis? Contact Dermatitis. 1997;37:121-4.

15. Diepgen TL, Weisshaar E. Contact dermatitis: epidemiology and frequent sensitizers to cosmetics. J Eur Acad Dermatol Venereol. 2007;21(2):9-13.

16. Mastromattteo E. Nickel and its compounds. In: Zenz C, Dickerson OB, Horvath EP Jr, editors. Occupational medicine. 3rd ed. St Louis: Mosby; 1994:563.

17. Hogan DJ, May J. Allergic Contact Dermatitis. Emedicine. Updated Mar 7, 2007. Available from http// www.emedicine.medscape.com.

18. Bhardwaj SS, Jaimes JP, Liu A, Warshaw EM. A double-blind randomized placebo-controlled pilot study comparing topical immunomodulating agents and corticosteroids for treatment of experimentally induced nickel contact dermatitis. Dermatitis. 2007;18(1):26-31.

19. Saripalli YV, Gadzia JE, Belsito DV. Tacrolimus ointment $0.1 \%$ in the treatment of nickel-induced allergic contact dermatitis. J Am Acad Dermatol. 2003 Sep;49(3:):477-482.

20. Kalimo K, Lammintausta K, Viander M, Jansén CT. PUVA treatment of nickel contact dermatitis: effect on dermatitis, patch test sensitivity, and lymphocyte transformation reactivity. Photodermatol. 1989;6(1):1619.

21. Gawkrodger DJ, Healy J, Howe AM. The prevention of nickel contact dermatitis. A review of the use of binding agents and barrier creams. Contact Dermatitis. 1995;2:257-65.

22. Memon AA, Molokhia MM, Friedman PS. The inhibitory effects of topical chelating agents and antioxidants on nickel-induced hypersensitivity reactions. J Am Acad Dermatol. 1994;30:560-5.

23. Wöhrl S, Kriechbaumer N, Hemmer W, Focke M, Brannath W, Götz M, Jarisch R. A cream containing the chelator DTPA (diethylenetriaminepenta-acetic acid) can prevent contact allergic reactions to metals. Contact Dermatitis. 2001;44(4):224-8.

24. Narwane SP, Patel TC, Shetty YC, Chikhalkar SB. Drug Utilization and Cost Analysis for Common Skin Diseases in Dermatology OPD of an Indian Tertiary Care Hospital -A Prescription Survey. British Journal of Pharmaceutical Research. 2011;1(1):9-18.

25. Pathak AK. Drug Utilization Pattern for Skin Diseases in a Indian Tertiary Care Hospital - A Prescription Survey. Journal of Clinical and Diagnostic Research. 2016 Feb;10(2):FC01-5.

26. Prasad PS, Rudra JT, Vasanthi P, Sushitha U, Sadiq MJ, Narayana G. Assessment of drug use pattern using World Health Organization core drug use indicators at Secondary Care Referral Hospital of South India. Chris Med J Health Res. 2015;2:223-28.

Cite this article as: Divyashanthi CM, Kolasani BP, Jayabal P, Sasidharan P, Datchanamurthy B. WHO core prescribing indicators in patients with allergic contact dermatitis in a coastal town of South India. Int J Basic Clin Pharmacol 2017;6:61-5. 